\title{
SMART INDUSTRY REQUIRES FAST RESPONSE FROM RESEARCH TO INNOVATION
}

Factories of the Future (FoF) gradually advance towards reality. The theoretical concepts leave research laboratories and quickly find their field in industry. This paper introduces Smart Factory issues. The authors in its first part summarized information from research and main trends in the area of advanced manufacturing systems. Second part of the paper shows the results from authors own research conducted in co-operation of Mechanical Engineering Faculty of the University of Zilina and its Spin Off, The Central European Institute of Technology CEIT, a.s. The paper shows chosen results from implementation of research results in innovation of internal logistics in VW Group.

Keywords: Reconfigurable Manufacturing, Internet of Things, Smart Industry, Digital Twin, Mobile Robotic Systems.

\section{Introduction}

Since the eighties of the last century, investment capital flow was mainly directed to the countries with cheap labor. The current fast technological advancement is allowing for redirection of the investment capital flow back to the countries with highly educated workforce. The success in business is nowadays determined by brain, more than by hands.

The latest, massive wave of innovation is referred to as the fourth industrial revolution, and it's built upon the use of the most advanced information and communication technologies (ICTs), automation, and robotization of all areas of the industry.

Production factories are complex socio-economic systems. The world globalization aided and expedited the wide expanse of scientific knowledge, new methods and technologies around the world. The technological progress forces the producers to invoke a rapid transformation of the manufacturing environment. If the producers want to keep up their competitiveness, they need to think quickly, anticipate the future changes, dynamically adapt their business strategy and immediately implement the necessary changes. Only those who can keep up this attitude continuously and perpetually can become successful in the long term.

\section{Impact of globalization on the industry}

Globalization is a new phenomenon that brought a change of customer behavior, as well as swiftly growing demand for customization and personalization of products. These are causing rapid increase of variability and complexity in manufacturing. Variability is a factor that has a major impact on the growth of production costs. Each doubling of the number of variations causes a production costs increase of 20 to $35 \%$.

Research by [1] has shown that even with a small number of elements, it is possible to create a huge number of variant combinations. For example, in a mobile robotic system with a total number of 83 modules plus 9 equipment extensions available for a customer to choose from, as to create custom variations, there are 328693558050 variations of the mobile robotic system.

So called Mass Customization concept has become a new paradigm that's being applied to deal with the necessary product variability. Its principle is that the customer is offered lots of expanding variations of the existing product, produced with moreor-less the same costs as in mass production. Thus it doesn't stake on production of one product as in classical mass production, but rather banks on a highly variable production of one family of products, while keeping the competitive costs of a mass production and the economies of scale [2].

Customization and personalization of products represents a complex issue. Researchers are trying to solve it either by an appropriate design of the new products, also known as modular \& reconfigurable products, or by attempting to increase the flexibility of the manufacturing system, nowadays also known under the term Reconfigurable Manufacturing [3].

\footnotetext{
* ${ }^{1}$ Milan Gregor, ${ }^{2}$ Stefan Medvecky, ${ }^{1}$ Patrik Grznar, ${ }^{1}$ Tomas Gregor

${ }^{1}$ Department of Industrial Engineering, Faculty of Mechanical Engineering, University of Zilina, Slovakia,

${ }^{2}$ Department of Design and Machine Elements, Faculty of Mechanical Engineering, University of Zilina, Slovakia

E-mail: milan.gregor@fstroj.uniza.sk
} 


\section{Industrie 4.0}

The European Union started to systematically invest into research and development in the year 2004, to support competitiveness growth of the European industry. Through the European technological platform "ManuFuture EU", the extensive European research program named "Factories of the Future" was initiated. Under this program a new national movement focused on industrial innovation - later labeled as Industrie 4.0 - raised up in Germany.

Industrie 4.0 represents the major innovation program initiated in Germany, but also the pragmatic European ambition, a new platform for European research resources mobilization and deployment, for further competitiveness improvement. It's also referred to as the new industrial revolution [4 and 5].

The German strategic initiative was responded to by other EU member countries with their own innovation programs. Smart Industry for Slovakia [6] is a Slovak version of Industrie 4.0 program that respects the particularities, existing conditions and possibilities of our own domestic industry.

The core of Industry 4.0 is essentially the implementation of industrial innovations that are based on digitalization and digital technologies as such. These innovations are primarily concentrated in the research area of decentralized, autonomous, intelligent structures, that should bring synergetic effects to the industry and that are nowadays known as Cyber-PhysicalSystems (CPS). CPS represents a system of all the objects present in the production environment, from the material, through the machines, equipment, robots, sensors, buildings, logistic elements, devices and systems, up to finished products. All the objects within CPS are connected by communication network that, via internet, enables mutual communication while providing required communication services. CPS can thus not only "sense" information about the whole environment (both internal and external) via sensors, but it can also share the information through the given network. People can only communicate with such complex and sophisticated systems through appropriate interfaces that are allowing control through speech recognition, touch, or directly by thoughts, which are commonly known as HMI (Human Machine Interface).

\section{Smart Factory integrates Digital, Real and Virtual Factories}

Future factories will be further developed with the support of the three integrated worlds: real, virtual and digital. That creates conditions for the use of methods for global optimization of the complex industrial systems. By combining the three worlds representing Digital Factory, Real Factory and Virtual Factory, a completely new kind of manufacturing environment comes to existence. The system is most commonly referred to as Smart Factory, or in a wider sense as Smart Industry, as shown in Fig. 1.

Smart Factories must be designed as self-organizing systems, adopting the properties of living organisms (swarms, ants, bees, etc.). The concept of aforementioned systems is based on the architecture of Bionic manufacturing systems, similar to the architecture used by living organisms in the nature.

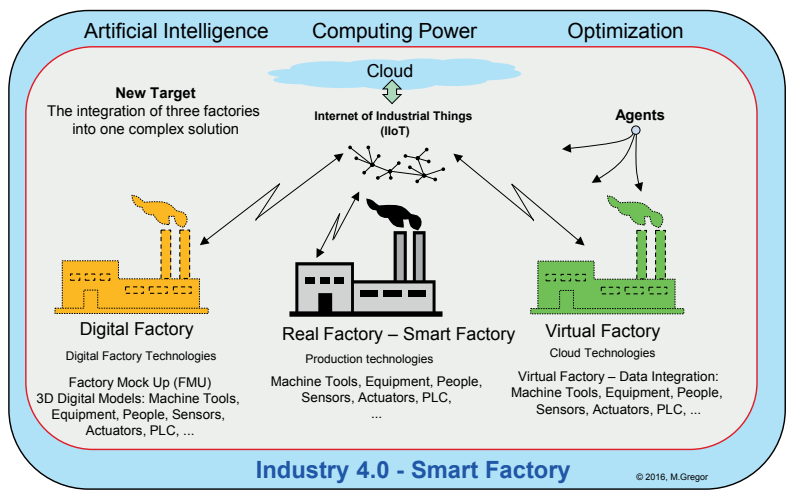

Fig. 1 Smart Industry Concept

\section{Technologies for Smart Factory}

Integration of ICTs with conventional industrial technologies extends the possibilities of the conventional technologies beyond what used to be considered possible. Aforementioned process of technological properties extension is referred to as the Convergence of Technologies and those technologies are thus called convergent technologies [7].

Use of the latest ICTs and sensors for organization and control of the advanced manufacturing systems became termed as Internet of Things (IoT) or Industrial Internet of Things (IIoT). Virtualized manufacturing environment, built upon the currently easily procurable big amounts of digital data from various sources, can now leverage the use of the indispensable phenomena, known as Cloud Services \& Cloud Computing. It represents a new IT (Information Technology) services proposition model via internet, where the IT functionalities are offered as an external service and are paid for based on the actual usage of computing power.

The new industrial revolution would be impossible without a brisk advancement of all the various disciplines, those being for example: artificial intelligence, nanotechnologies, robotics, fast computing systems, sensors, reconfigurable systems, digital factory, big data, knowledge based systems, virtual reality, wireless sensor networks, computer simulation, new methods of recognition and identification, etc.

The progressive sensor systems are enabling the real time gathering of huge amounts of data, it's processing, analyses and new knowledge gains (knowledge based systems) that can be used 
for prediction of future behavior of the industrial system and for advanced decision making. These systems are usually labeled as Big Data Analytics.

Actuators enable the fulfillment of aforementioned decisions (execution of control commands), which further allows the autonomous response to both internal and external stimuli, thus concluding the backward control loop, which is the basis for the autonomous behavior of industrial systems [8].

\section{New concept of Smart Factory}

The intensively increasing numbers of individual customers demanding to modify the details of their products continuously until the final point of the assembly want to be present at the birth of their personalized products. To cope with the ever-growing complexity of the production, the researchers are experimenting with the replacement of today's rigid and outdated production lines by a cluster of autonomous workstations, so called Islands

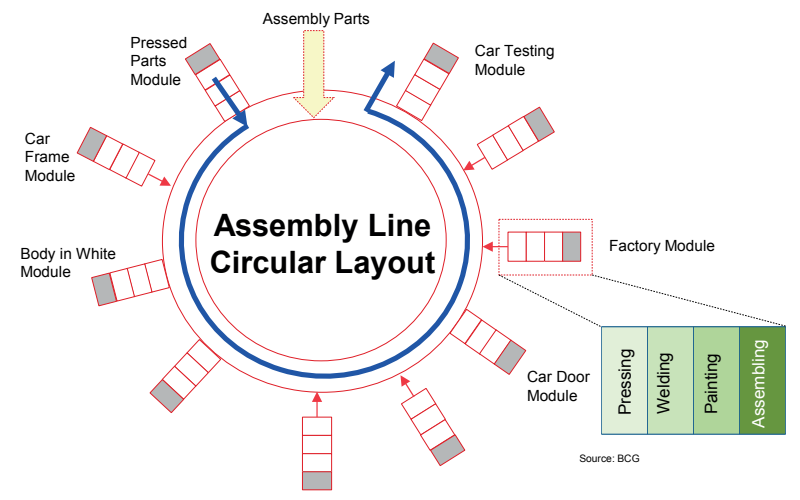

Fig. 2 Circular organization of production according to BCG of Competence [1]. We can imagine those as virtual production lines, small and highly flexible production units, dynamically being formed and ceasing to exist according to the current needs of the system.

Traditional manufacturing systems used to be designed as linear systems. Today, it's being considered that the future factories could use "circular" structures that would allow the suppliers to directly connect to the production line. This type of structures was named Factory on Demand by Dashchenko [9], and the foresight of its structure for automobile factories, as proposed by Boston Consulting Group (BCG), is shown in Fig. 2.

The manufactured product will act within the production environment as an intelligent entity, capable of communication with its surroundings, able to self-organize its individual production process completely autonomously. Such product will, for example, be able to define the specifics of its own production process, to allocate the required production capacity within the Islands of Competence, or to call-in a mobile robot that will provide for its transport within the production process. The complex relations between individual entities trigger condition known as emergence, in other words, a state in which it's hard, or even impossible to predict the future behavior of such complicated systems, because of their emergent properties. The aforementioned properties are those which are impossible to be explained in a reductionist manner, that is to say, by the actions of the constituent elements of the system. Therefore, the researchers are experimenting with a new approach to the design of control systems (Multiagent Systems, MAS) - based on relative autonomy of individual elements acting within the production system - that will resemble the behavior of intelligent, living organisms. In manufacturing, virtual representatives of the real objects, presently named as Digital twins, will therefore exist in addition to the real objects.

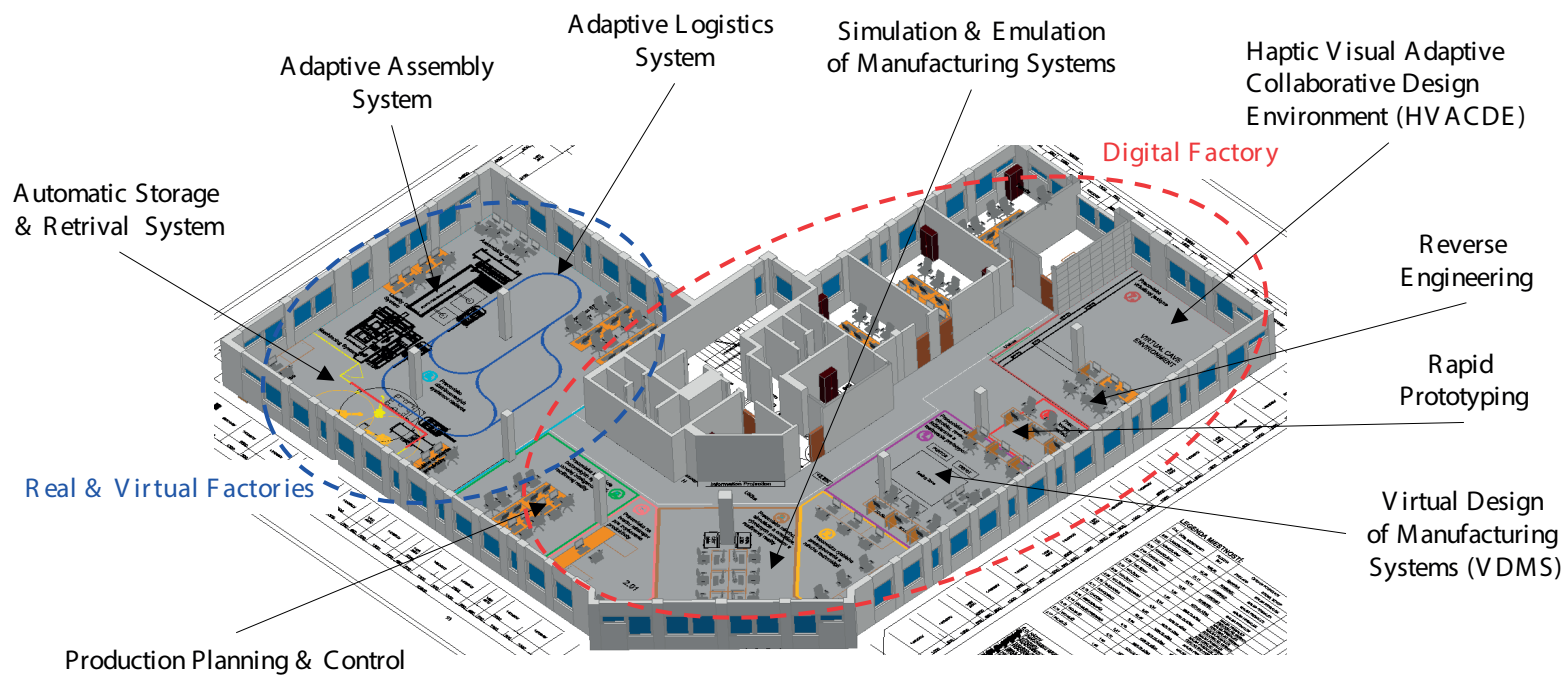

Fig. 3 ZIMS Layout 
We refer to this dual representation of the manufacturing as virtual manufacturing.

\section{Response of research to the industrial requirements}

The Faculty of Mechanical Engineering at the University of Zilina in cooperation with the Central European Institute of Technology (CEIT) are building a joint research laboratory for the Factory of the Future, called ZIMS (Zilina Intelligent Manufacturing System). ZIMS (Fig. 3) has become a new platform supporting research and development of state-of-the-art technologies and methods, experimentation and subsequently their transformation into new innovations for industry.

\section{Adaptive Logistics Systems (ALS) - from concept to innovation}

Researchers of the University of Zilina and CEIT use technological reflector (Fig. 4) in form of Hype Curve [10] when formulating the trends of technological advancement.

Based on the Hype Curve, the time interval of the use and the rules of efficiency \& profitability, the prioritization of alternative technologies is carried out. With regard to defined technological priorities, an innovation and implementation road map for the given innovation is consecutively punctiliously specified. Such a case, explained on an example of MRS (Mobile Robotic System) innovation, is shown in Fig. 5.

In cooperation of CEIT and the University Science Park of the University of Zilina, a concept of holonic internal logistics control system (Fig. 6) for Smart Factory is being developed within the ZIMS workplace [11 and 4].

The logistics is made up of separate components, holons, which possess characteristics such as ability to act autonomously, to communicate with each other, to gather data via sensors, to learn, to make decisions based on the current state of the production system, to optimize and predict future proceedings of the production system or to solve control tasks of its own level of hierarchy. There's even talk of cognitive logistics, in the field of today's logistics research. Adaptive logistics must therefore possess the capability to change not only its own structure, but also its functions and capacity [12 and 13].

The first and necessary prerequisite for adaptability is proper, practical modularity of logistic means, which is often also a condition for quick reconfigurability of the logistics system.

The developers use digital models of the production system for the design and examination of the dynamics of the logistics system. Those are created in the simulation-emulation environment of Ella software package developed by a startup

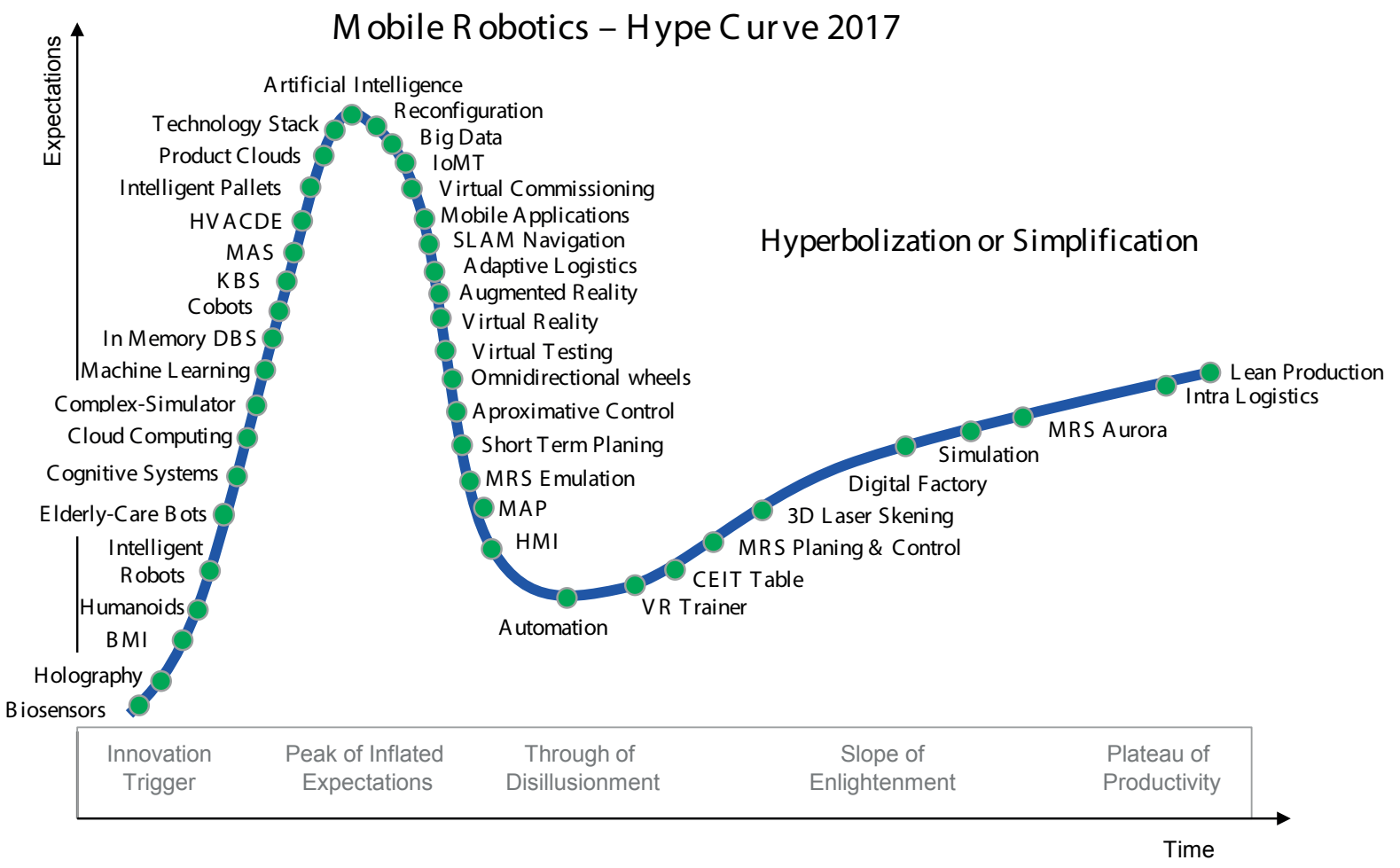

Fig. 4 Technological Hype Curve for the field of adaptive logistics 


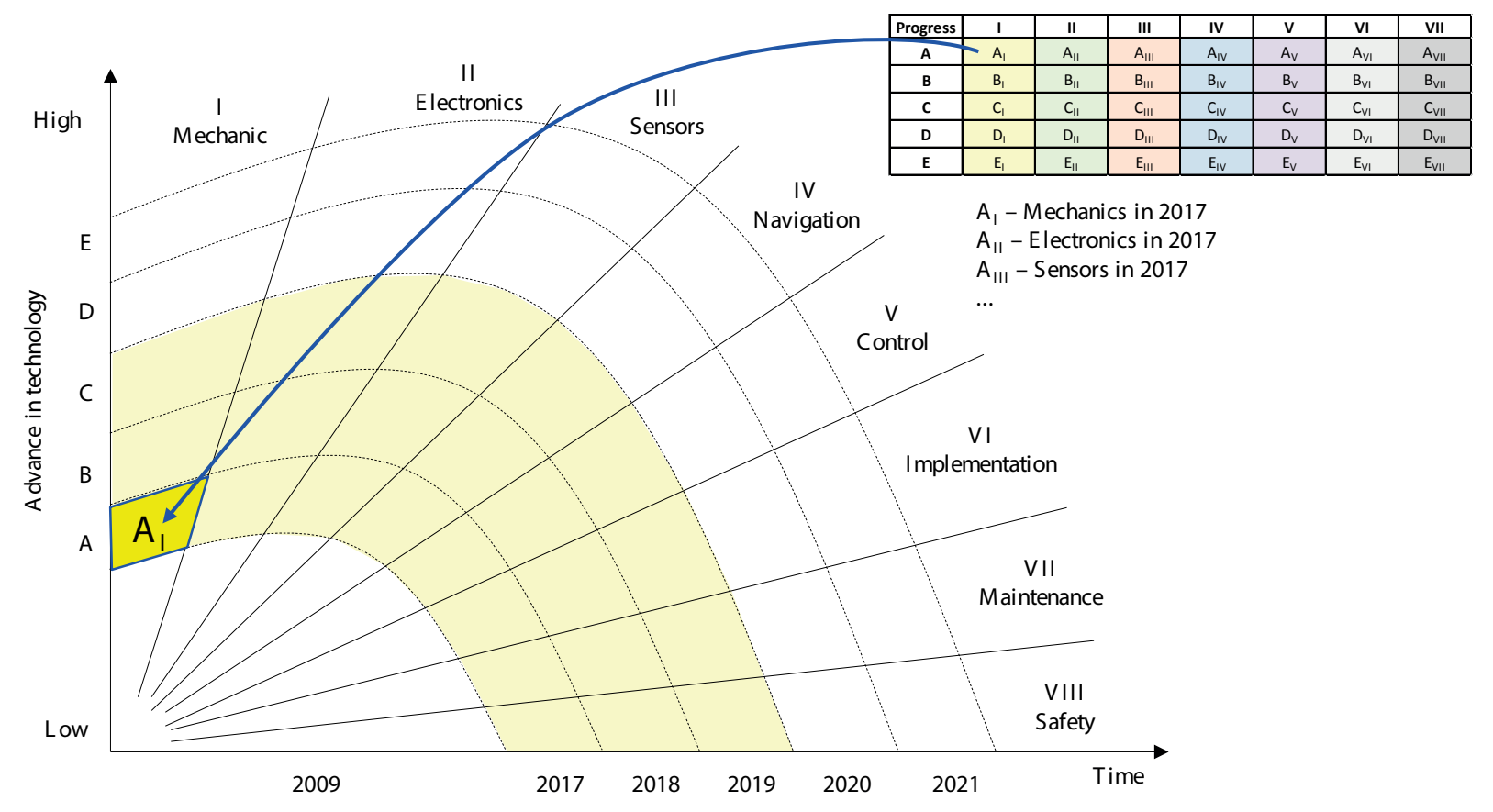

Fig. 5 Graphical form of a Road Map for MRS innovations

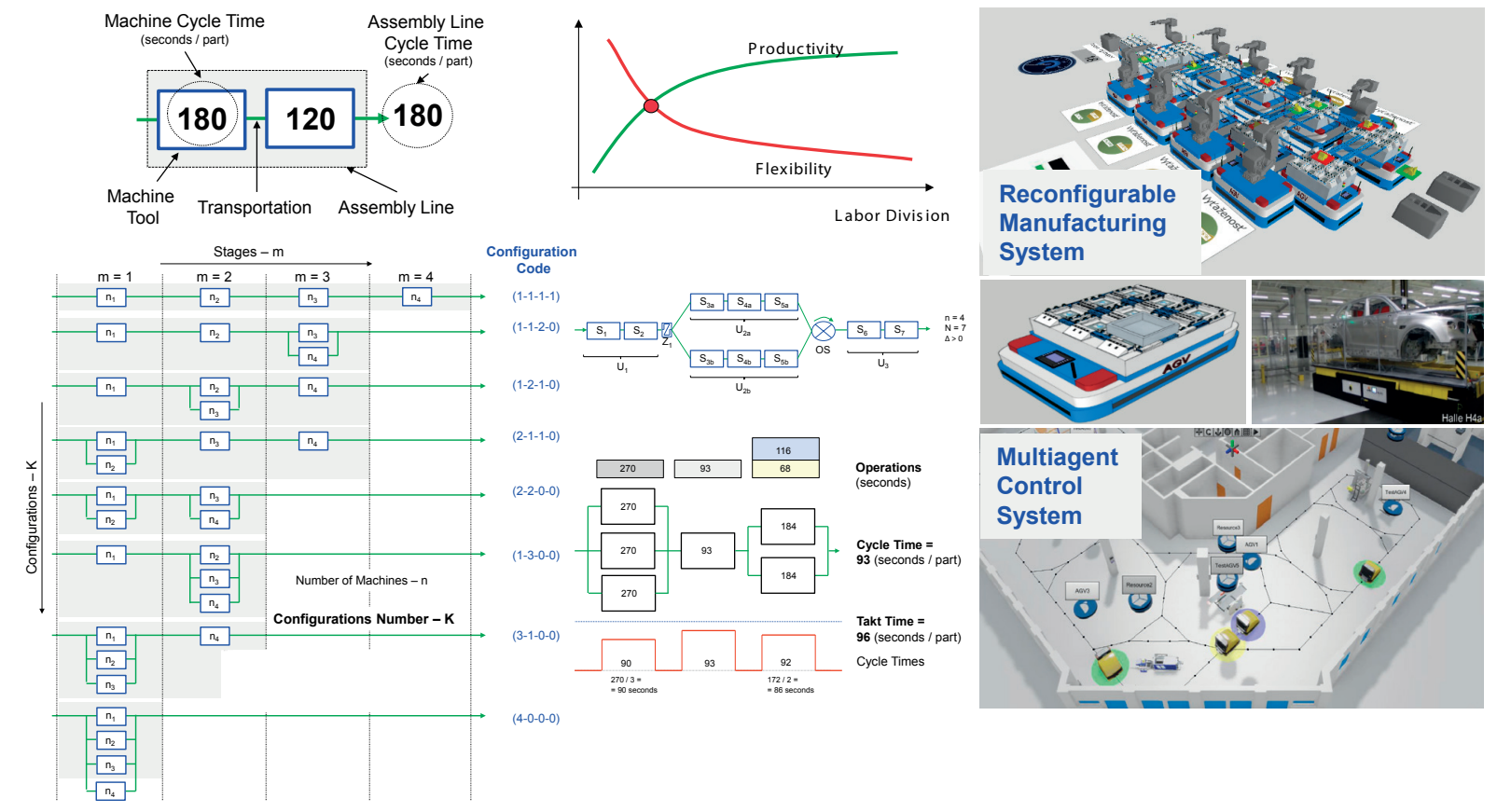

Fig. 6 New concept of ALS

company Edgecom (www.edgecom.eu). The process of complex logistic solutions development leverages the locally developed Haptic Visual Adaptive Collaborative Design Environment (HVACDE) that allows the designer to visualize digital models within the design process, and to gain "real" impulses, feelings and perceptions via immersion, as if he was working in a real logistic environment [14 and 15] .

Every real and important MRS object is represented by its virtual twin, also called agent. Multi-agent control system for reconfigurable logistics systems and mobile robotic systems was developed by [4]. 
Mobile robotic system, in addition to the basic functions (physical layer of the product), has the ability to perform its functions intelligently (smart layer). While performing its functions, it can communicate with other entities (communication layer) and based on this communication it can make better, more informed decisions. Such a complex environment we refer to as the product cloud [16]. Thanks to the advanced technologies of today, the functionality of the MRS grows and it can now decide internally which functionality (technology) it will use to accomplish any given task. Set of mentioned technologies is also called Technology Stack [17]. The ALS (Automated Logistics System) solution that's being developed leverages autonomous logistic tractors under the name of Aurora (developed by CEIT) that were designed as modular systems, as shown in Fig. 7.
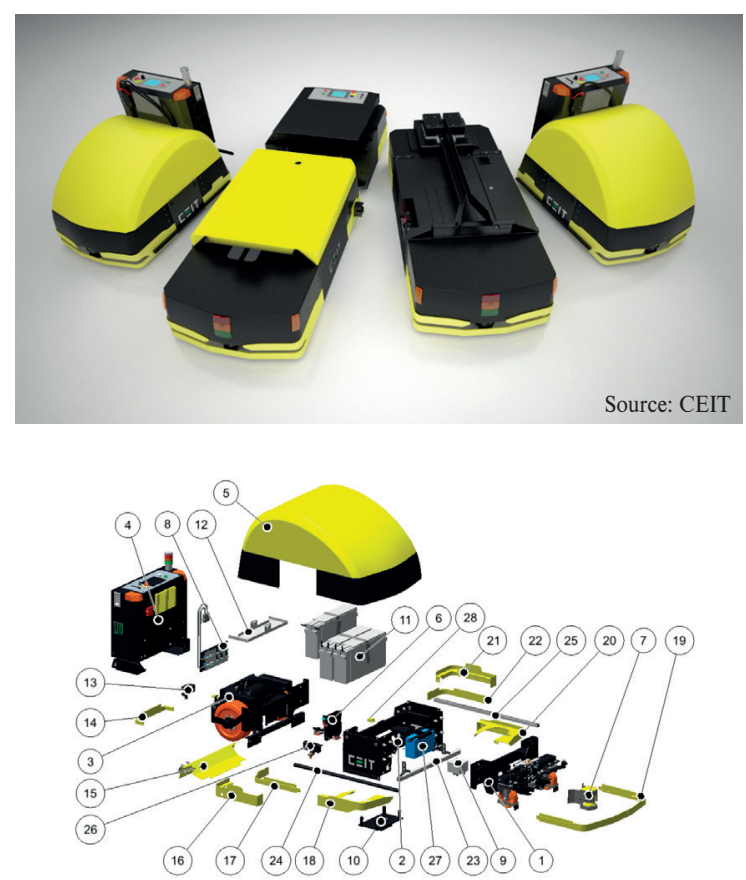

Fig. 7 Logistic tractors from Aurora program (Source: CEIT Archive)

Set of superstructures and accessories (Fig. 8) extends the capabilities of CEIT_MRS, and supports functions focused on reconfigurability of the whole system.

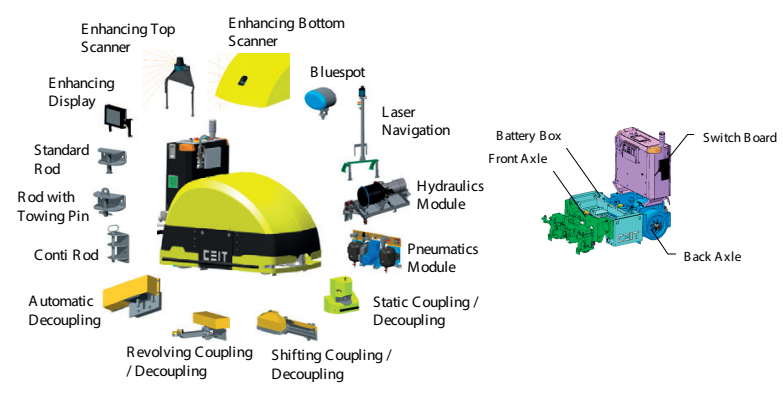

Fig. 8 Example of extension elements (Source: CEIT Archive)
One example of the reconfigurability possibilities is the C-frame extension equipment (Fig. 9).

Deployment of an existing Aurora system in VW Group factories is shown in Fig. 10.

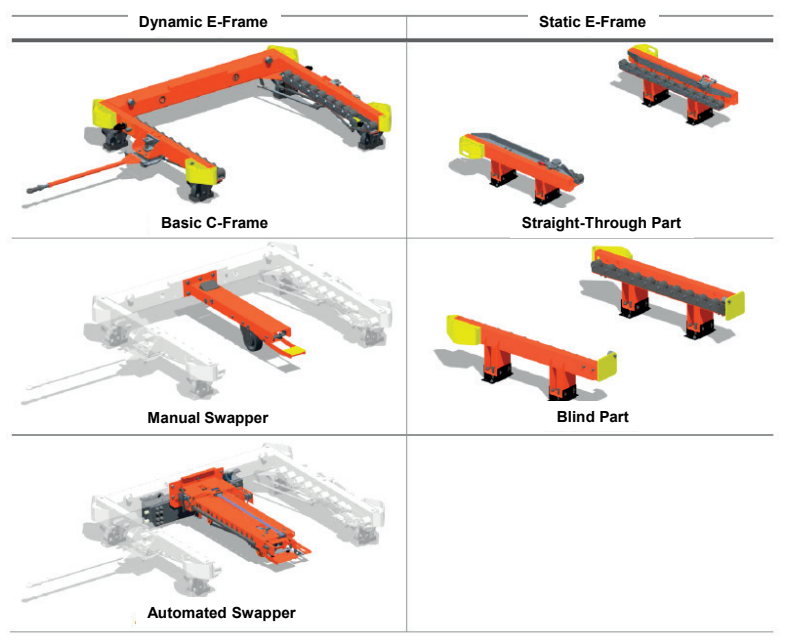

Fig. 9 Example of reconfigurable C-frame (Source: CEIT Archive)

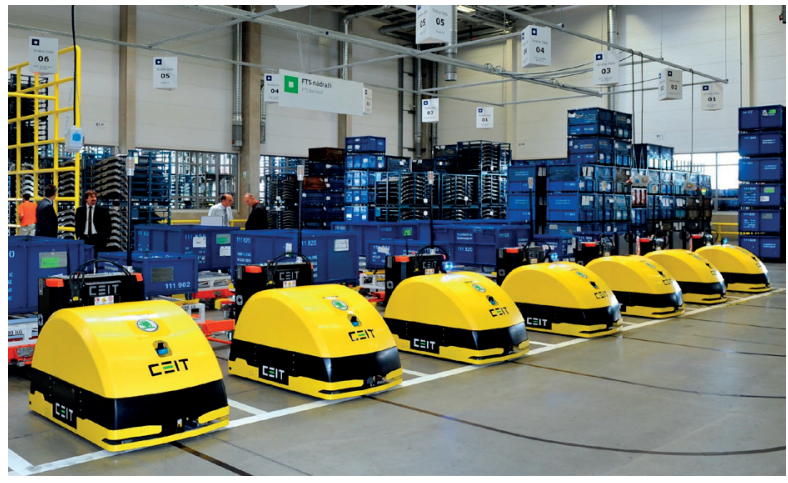

Fig. 10 CEIT logistics system working in automobile industry

\section{Conclusion}

The nature works as a complex, self-organized, holonic system. Even humans are made up of small, autonomous entities - holons that together create bigger, self-organized, complex units, which create a complex holonic system - a human.

The nature has created biological systems and via natural evolution it allowed for their further development towards the highest form of organized mass - intelligent systems.

Biological systems represent the most effective and most efficient production systems known to mankind today. These systems serve the scientists as role models, in creation of artificial mechanisms imitating nature, aimed for manufacturing of new products. 
New break-through technologies have started a transformation of today's manufacturing. Future production and its organization must be seen in a new light, we must look at it from a completely different perspective, with complexity and an overview of the future.

The changes that evoke the transformation of the factories constitute an unequivocal stage of the development. The new stage of development, as well as the previous stages, brings immensely positive prospects along with great risks.

\section{Acknowledgements}

This paper was supported by research project "Reconfigurable Logistics System for Manufacturing Systems of the New Generation of Factory of the Future (RLS_FoF) “, No. APVV-14 0752, co-financed by the Slovak Agency for R\&D Support.

\section{References}

[1] GREGOR, M., MEDVECKY, S., MICIETA, B., MATUSZEK, J., HRCEKOVA, A.: Digital Factory (in Slovak), SLCP Zilina, KRUPA Print 2007, p. 148, 2003, ISBN 80-969391-5-7.

[2] GREGOR, M., MEDVECKY, S.: Digital Factory - Theory and Practice, Engineering the Future. SCIYO, 2010, p. 22, ISBN 978-9537619-X-X.

[3] KOREN, Y:: The Global Manufacturing Revolution, John Willey \& Sons, New Jersey, 2010, p. 399, ISBN 978-0-470-58377-7.

[4] DURICA, L.: Multiagent Logistics System with the Implementation in Virtual Reality (in Slovak), Dissertation Thesis, Department of Industrial Engineering: Faculty of Mechanical Engineering: University of Zilina, 2016, p. 181.

[5] WESTKAMPER, E., ZAHN, E.: Conductible Production Companies. The Stuttgart Company Model (in German), Springer Verlag Berlin, p. 321, 2009, ISBN 978-3-540-21889-0.

[6] GREGOR, M.: CEIT MRS 2020. CEIT Mobile Robotics. R\&D Routing Till 2020, (in Slovak), CEIT, p. 66, CEIT-S010-09-2015.

[7] MICIETA, B., GASO, M., KRAJCOVIC, M.: Innovation Performance of Organization, Communications - Scientific Letters of the University of Zilina, vol. 16, No. 3A, 2014, 112-118. ISSN 1335-4205.

[8] HALUSKA, M.: Reconfigurable Manufacturing Systems (in Slovak), Dissertation Thesis, Department of Industrial Engineering, Faculty of Mechanical Engineering, University of Zilina, 2015, p. 168.

[9] BAUERNHANSL, T. et al.: Industry 4.0 in production, Automation and Logistics. Application - Technologies - Migration (in German), Springer Verlag, Wiesbaden, p. 648, 2014, ISBN 978-3-658-04681-1.

[10] KRAJCOVIC, M. et al.: Intelligent Manufacturing Systems in Concept of Digital Factory, Communications - Scientific Letters of the University of Zilina, vol. 15, No. 2, 2013, 77-87, ISSN 1335-4205.

[11] GREGOR, M., KRAJCOVIC, M., GREGOR, T., GRZNAR, P., HALUSKA, M., DURICA, L.: Smart Logistics. New Technologies for Logistics, Study. Department of Industrial Engineering, Faculty of Mechanical Engineering, University of Zilina, CEIT, j.s.c, p. 66, 2015, Research Project No. APVV-14-0752.

[12] GREGOR, T., PATKA, J., GREGOR, M.: Mobile Robotic Systems - the Innovation Movement Started, Methods and Techniques of Production Processes Control. Monography, University of Bielsko-Biala, 101-114, 2016, ISBN 978-83-65182-37-1.

[13] AUDI RETHINKS PRODUCTION: 2015, 29. 5. 2015, http://audi-encounter.com/magazine/smart-factory/02-2015/148-smartfaction.

[14] GREGOR, M., MEDVECKY, S.: CEIT 2030. CEIT Technology Trends till 2030 (in Slovak), Zilina, Study, CEIT-S002-03-2015, 2015, p. 101.

[15] SMART INDUSTRY FOR SLOVAKIA: Ministry of Economy, Slovak Republic. 39 p. http://www.smartindustrysk.com/, 20. January, 2017.

[16] DASHCHENKO, O.: Analysis of Modern Factory Structures and Their Transformability, Ed., Springer Verlag: Berlin: Heidelberg, 395-422, 2006, ISBN 978-3-540-29391-0.

[17] KRAJCOVIC, M., STEFANIK, A., DUlinA, L.: Logistics Processes and Systems Design Using Computer Simulation, Communications - Scientific Letters of the University of Zilina, vol. 18, No. 1A, 2016, 87-94, ISSN 1335-4205. 